revista ANTHROPOLÓGICAS

Ano 23, 30(2): 5-37, 2019

\title{
Por uma Epistemologia dos Museus Indígenas: temas e problemas
}

Alexandre Oliveira Gomes ${ }^{a}$

O artigo visa apresentar problemas teóricos e epistemológicos sobre o universo dos museus e processos museológicos indígenas a partir de dados, informações e experiências etnográficas oriundas de investigações efetuadas durante cerca de 15 anos sobre este campo de pesquisas. Tratamos de questões pertinentes para a constituição de uma antropologia dos museus indígenas, situando temas como a reflexividade, a coautoria, a simetria, a horizontalidade, as formas de validação do conhecimento antropológico e a representação; como aspectos importantes para a constituição de uma abordagem etnomuseológica em meio à diversidade de museus indígenas no Brasil.

Museus Indígenas, Antropologia, Etnografia, Epistemologia.

Em outra ocasião, levaram-me para visitar uma grande casa que os brancos chamam de museu. É um lugar onde guardam trancados os rastros de ancestrais dos habitantes da floresta que se foram há muito tempo. Vi lá uma grande quantidade de cerâmicas, de cabaças e de cestos; muitos arcos, flechas,

zarabatanas, bordunas e lanças; e também machados de pedra, agulhas de osso, colares de sementes, flautas de taquara e uma profusão de adornos de penas e de miçangas. Esses bens, que imitam os dos xapiri, são mesmo muito antigos e os fantasmas dos que os possuiram estão presos neles. Pertenceram um dia a grandes xamãs que morreram há muito tempo. As imagens desses antepassados foram capturadas ao mesmo tempo que esses objetos foram roubados pelos brancos, em suas guerras. Por isso digo que são posses dos espiritos.

Davi Kopenawa \& Bruce Albert

a Professor-Assistente do Departamento de Antropologia e Museologia da UFPE. Pesquisador do NEPE (PPGA-UFPE). Email: amanayparangaba@yahoo.com.br. 
Os museus indígenas foram constituindo-se em nosso horizonte analítico paulatinamente ao adensamento das relações estabelecidas com interlocutores, sujeitos e coletividades étnicas que protagonizam estes processos. Essas relações são históricas e socialmente condicionadas e, ao mesmo tempo, individuais e coletivas. Aconteceram desde determinadas problemáticas, diferentes pontos-de-vista e em momentos específicos das vidas deles e das nossas. As relações que geraram estas pesquisas ocorreram no entrecruzamento entre nossas existências. São, portanto, construções coletivas, e o que chamamos de 'dados', em nossa perspectiva, são relacionais e produzidos em co-autoria, resultantes de situações sociais pelas quais perpassam diferentes agências e contextos.

Reconhecemos as problemáticas oriundas do questionamento da retórica da representação, analisando questões como (co)autoria e autoridade em nosso próprio texto etnográfico. $\bigcirc$ refino na análise antropológica reside no rigor referente à construção e trato dos dados e informações, na relação entre argumentos e evidências, na definição de critérios de cientificidade e nas formas de validação do conhecimento antropológico, através da utilização de procedimentos metodológicos e categorias analíticas apropriadas às realidades que intentamos compreender (Jacobson 1991). Abordagens conectadas aos atuais desafios epistemológicos da disciplina precisam assumir algumas assertivas emblemáticas ao nosso ofício: admitir que o antropólogo faz parte e é sujeito no real estudado; é um ator social fundamental na dinâmica das interações e na agência dos/com os sujeitos e grupos com quem vivencia experiências de pesquisa; que é necessário, ao envidar esforços pela reflexividade, evitar o perigo da auto-etnografia e da autobiografia e, ao mesmo tempo, exercitar o distanciamento e a aproximação para o exercício da reflexão antropológica. Consideramos, em nossa abordagem sobre os museus e processos museológicos indígenas como campo de pesquisas, que o conhecimento antropológico é fortemente relacional e co-produzido entre os sujeitos envolvidos nas situações de 'trabalho de campo'. 
No estudo, originado de nossa dissertação de mestrado, intitulado Aquilo é uma coisa de indio: objetos, memória e etnicidade no Museu dos Kanindé (CE), analisamos a relação entre cultura material, construção social da memória e a organização das diferenças étnicas entre o povo indígena Kanindé do Sítio Fernandes, município de Aratuba, Estado do Ceará. Meu foco era compreender a relação entre o processo de emergência étnica e a criação do museu indígena, ocorrida em 1995, mesmo ano em que eles passaram a se mobilizar por reconhecimento como povo indígena frente ao Estado brasileiro (Gomes 2016). Entre os dados analisados, destacaram-se os objetos, as memórias orais e os documentos do acervo do Museu dos Kanindé, além da pesquisa de campo etnográfica realizada através da observação participante durante um período de seis meses, entre março e agosto de 2011. O interesse em descrever e entender como se davam os processos de deslocamento e recontextualização de objetos (Gonçalves 2007; Stocking Jr. 1985), mas também as dinâmicas étnicas frente às memórias e patrimônios, me possibilitou perceber, não os sistemas - sejam de significados ou de funções - mas os fluxos e contra fluxos, as variações de sentido, os diferentes usos e as ressignificações dos objetos, de acordo com os diversos sujeitos e grupos em suas variadas interações sociais (Gomes 2012:105-106). Em nossa Tese de Doutorado, intitulada Museus indígenas, mobilizações étnicas e cosmopolíticas da memória: um estudo antropológico (Gomes 2019) ${ }^{1}$, aprofundamos este escopo analítico de viés etnomuseológico, mas voltamos nossa atenção à análise de dados provenientes de situações sociais em campos multissituados e em meio à múltiplas relações interétnicas ${ }^{2}$. Avançamos na constituição de ferramentas analíticas alicerçadas nas experiências museológicas dos povos indígenas, antenadas às especificidades heurísticas dos museus indígenas enquanto campo de pesquisas, às problemáticas da reflexividade e do questionamento do universalismo da dualidade entre natureza e cultura, tal como formulada pelo pensamento ocidental moderno. Uma pergunta, feita em 2012 ao final da pesquisa de mestrado, permaneceu atual: como construir um 
cabedal conceitual frente à diversidade de experiências museológicas dos povos indígenas no Brasil?

\section{Museus indígenas, mobilizações étnicas e cosmopolíticas da memória}

O processo investigativo que originou minha tese de doutorado em Antropologia resultou de um longo percurso investigativo efetuado entre 2006 e 2018, período em que atuei junto a diversificados processos museológicos indígenas no Brasil. Apesar de ter efetuado narrativas e análises sobre fatos e processos ocorridos em diferentes locais, a argumentação partiu dos contextos dos Estados do Ceará e de Pernambuco, na região Nordeste do Brasil, onde a pesquisa se deu mais fortemente. Nesta investigação sobre a diversidade de memórias indígenas, analisei as mobilizações étnicas e as dinâmicas cosmológicas associadas aos processos de 'apropriação' e 'tradução' dos museus por populações indígenas, por meio da compreensão de como ocorrem as ressignificações das noções de 'patrimônio' e 'cultura', a partir da experiência do Museu dos Kanindé, criado no ano de 1995, no Sítio Fernandes, zona rural no município de Aratuba (CE).

Durante o período da pesquisa de campo, ocorreu a criação da Rede Indígena de Memória e Museologia Social, formalmente constituída em dezembro de 2014, na cidade do Recife (PE). Com sua ampliação, passei a atuar como assessor acompanhando vários museus indígenas e as atividades da própria Rede, composta por um conjunto de iniciativas museais indígenas de diferentes regiões brasileiras. Tal fato possibilitou que uma gama de informações e dados fossem construídos, para além das realidades locais, na escala das múltiplas trocas oriundas das interações que passaram a ocorrer com a criação desta instância de mobilização e organização coletiva. Com isso, um diversificado conjunto de intercâmbios de ideias, conhecimentos, objetos etc., suscitou um quadro inesperado que conduziu a pesquisa de campo e a etnografia para novas situações. $O$ resultado desta pesquisa foi um estudo interdisciplinar sobre museus e memórias indígenas que 
parte da perspectiva teórica da Antropologia que se constituiu em interface com técnicas de pesquisa e conceitos da História e da Museologia, além de flertar com as Artes, a Arqueologia e o Audiovisual (Gomes 2019).

Neste estudo busco compreender a relação entre memória e etnicidade através da análise da ação museológica indígena nas experiências protagonizados por populações nativas no Brasil. Nos esforçamos para formular conceitos apropriados ao estudo antropológico das experiências museológicas e de memória dos povos indígenas, efetuando etnografias em processos vem sendo chamados por alguns pesquisadores de 'ndigenização' ou 'descolonização de museus' (Gomes \& Vieira Neto 2009; Gomes 2012, 2016a, 2016b, 2016c e 2019; Roca 2015a e 2015b; Gomes \& Athias 2018).

Apresento uma análise sobre o campo dos museus indígenas no Brasil, com ênfase a partir de 2012, quando terminamos a pesquisa que resultou em nossa dissertação de mestrado. Deste ano em diante acompanhamos a constituição de dinâmicas redes de troca e articulação entre experiências situadas em diversos Estados, além do Ceará e de Pernambuco, em São Paulo, Rio de Janeiro, Amapá, Amazonas, Rondônia, Rio Grande do Norte, Paraíba, Piauí e outros, abrangendo as cinco regiões brasileiras no final de 2017, quando aconteceu o III Fórum Nacional de Museus Indígenas, no Piauí.

Dentre os materiais empíricos produzidos e analisados, destacamos os dados compilados a partir da realização de três encontros nacionais, nos anos de 2015 (no Museu dos Kanindé, município de Aratuba, CE), 2016 (na aldeia Mina Grande, povo Kapinawá, município de Buíque/PE) e 2017 (na localidade de Nazaré, onde vivem os Tabajara e Tapuyo-Itamaraty, município de Lagoa de São Francisco, PI), além de diversos outros encontros e intercâmbios estaduais, nos quais elaboramos uma série de registros documentais e imagéticos. As noções de 'etnomusegrafia', 'ação museológica indígena', 'tradução' e 'apropriação' - fundamentos para uma 'cosmopolítica da memória' foram amadurecidas no processo investigativo, apresentadas na Tese 
enquanto ferramentas analíticas para a compreensão das problemáticas, hipóteses e argumentações. Identificamos 43 iniciativas museológicas entre populações indígenas no Brasil, coletando dados com seus organizadores e integrantes, pari passu à realização das pesquisas de campo. Elaboramos com este material uma sistematização cartográfica (mapa) e uma tabela com dados visando apresentar uma caracterização geral dessas experiências.

A junção de termos designativos aos processos de apropriação dos museus pelos índios já vem ocorrendo em círculos científicos e entre integrantes dos movimentos indígenas. Referidos também como 'museus tribais' (Clifford 2009; Scheiner 2012), 'museus étnicos' (Meneses 1993) e/ou 'museus indígenas' (Freire 1998; Vidal 2008 e 2013; Gomes \& Vieira Neto 2009; Gomes 2012, 2016, 2019), problematizamos o significado destes processos museológicos e da própria noção de museus indígenas, como categoria nativa (usada pelos indígenas para definir determinados processos que protagonizam), fenômeno social (resultando de determinadas relações, práticas e interações sociais) e categoria de classificação (tipologia de museu). Associamos esta análise aos dados e situações etnográficas vivenciadas através de uma pesquisa de campo de longa duração, que se deu através da observação participante junto ao universo das experiências dos povos indígenas com as questões museológicas entre 2006 e 2018.

Entre 2010 e 2012 cursei o mestrado no Programa de Pós-Graduação em Antropologia do Departamento de Antropologia e Museologia da Universidade Federal de Pernambuco (PPGA/DAM/UFPE), com a proposta de analisar a relação entre processo museológico e mobilização étnica, através do estudo dos sentidos, historicidade e ressignificação de objetos e memórias no Museu dos Kanindé ${ }^{3}$. Atribuo à prolongada reflexão sobre as experiências a partir dali vivenciadas como um fator crucial no amadurecimento das ideias apresentadas nesta tese e no desenvolvimento da noção de 'etnomuseografia'. O conceito de etnomuseografia proposto se originou da fusão da observação participante no trabalho de campo com a utilização de métodos 
museográficos na construção de dados para a descrição etnográfica, que estão associados ao processo de constituição de autorrepresentações e de uma 'cosmopolítica da memória' efetuadas na 'ação museológica indígena'.

Antecedido de uma longa experiência profissional nos campos da História e da Museologia, vivenciada durante 10 anos no Museu do Ceará (2000/2010), em Fortaleza, a partir de 2010 estabeleci vínculo profissional e acadêmico com a Universidade Federal de Pernambuco/UFPE, nas condições de estudante do Programa de Pós-Graduação em Antropologia (no qual passei a integrar o Núcleo de Estudos e Pesquisas sobre Etnicidade/NEPE), professor-assistente do Departamento de Antropologia e Museologia (Campus Recife) ${ }^{4}$ e professor-temporário da Licenciatura Intercultural Indígena (Centro Acadêmico do Agreste/Campus Caruaru) ${ }^{5}$. Neste período de 20 anos, me dediquei paralelamente à uma intensa agenda de trabalhos, com uma dedicação especial ao amadurecimento de reflexões teórico-metodológicas sobre os museus indígenas como objeto de estudo e campo de pesquisa e ação, com o objetivo de consolidar uma antropologia dos museus indígenas conectada a diversidade destas experiências por meio de uma abordagem etnográfica e de longa duração.

Durante a pesquisa de campo e a redação final da Tese, nossa compreensão sobre as dinâmicas dos museus indígenas se transformou tenazmente. $\mathrm{O}$ campo empírico se ampliou e diversas outras problemáticas surgiram por conta da maior abrangência dos processos étnicos acompanhados a partir da observação participante efetuada junto a variadas experiências de museus indígenas no Brasil. O diálogo extrapolou o território nacional. Entre abril e agosto de 2017, aprofundei olhares sobre os museus indígenas vivenciando a realidade dos museos comunitarios entre pueblos indígenas e mestizos congregados na Unión de Museos Comunitarios de Oaxaca, a UMCO, sediada na cidade de Oaxaca de Juaréz, capital do Estado de Oaxaca, sul do México.

O estágio sandwich foi realizado no Centro de Investigaciones e Estudios Superiores em Antropología Social, Unidad Pacifico Sur (Estado de 
Oaxaca). Constituiu a culminância de um diálogo empreendido como parte da pesquisa desde 2014, quando estabelecemos uma interlocução junto aos antropólogos que desempenham a função de assessores da UMCO, da Unión de Museos Comunitarios y Ecomuseos de Mexico e da Red America de Museos Comunitarios, Cuauhtémoc Camarena Ocampo e Teresa Morales Lersch, duas referências mundiais na pesquisa antropológica em museologia comunitária e, especialmente, de museus entre populações nativas na América6 .

Em meio ao nível de alteridade que esta experiência me proporcionou, percebi com maior clareza problemas afins aos que vinha estudando entre as populações indígenas no Brasil. Essa experiência me fez refletir, a partir de outros ângulos, sobre minha própria trajetória enquanto pesquisador e sujeito do campo museológico brasileiro com atuação profissional em áreas correlatas, como a docência (em âmbitos da educação formal e não-formal), a gestão museal (pública e comunitária) e o terceiro setor (ONG's, associações indígenas e entidades indigenistas).

A opção pela realização deste sandwich em Oaxaca se deu por conta do amadurecimento e longevidade dos trabalhos efetuados pelos museus entre os pueblos naquele Estado mexicano, reconhecido nacional e mundialmente pelo pioneirismo global no tocante aos museus comunitários indígenas. Constituiu também um alargamento do escopo de interlocução e a ampliação dos horizontes analíticos e teórico-metodológicos, na medida em que me apropriei da bibliografia mexicana sobre a temática e vivenciei durante o período de cinco meses em pesquisas de campo, o contexto dos museus comunitários e das populações congregadas na Unión. Acompanhei as atividades dessa organização, que foi a primeira rede de museus indígenas criada na América (em 1991), viajando com seus integrantes e com sua equipe de assessoria, que cheguei a compor, na condição de tallerista. Ministrei oficinas junto a jovens e crianças estudantes de escolas em pueblos e museus partícipes da Unión, especialmente nas regiões da Sierra Mixteca, na Sierra Norte Zapoteca e nos Valles Centrales de 
Oaxaca e Tlacolula, atividades que faziam parte do projeto que então desenvolviam, Nuestra visión del cambio?.

No Brasil, a investigação da Tese foi realizada entre 2014 e 2018. Durante esse período, se consolidaram uma série de processos relacionados aos museus indígenas em diferentes Estados no Brasil. $\mathrm{Na}$ região Nordeste, um conjunto de iniciativas se fortaleceu e consolidou-se, desempenhando um papel preponderante na organização de uma rede nacional de museus indígenas, que fomentou o diálogo, o intercâmbio e as trocas de conhecimentos envolvendo indígenas de vários povos. Este protagonismo deslocou para o Nordeste o principal pólo para onde convergiram com uma maior dinamicidade as práticas e diálogos sobre os museus indígenas no país. Paralelamente, a experiência museológica dos Kanindé de Aratuba emergiu para a obtenção de uma grande visibilidade nacional, passando a ser reconhecido como um dos principais e mais ativos museus indígenas no país, cujos integrantes estiveram diretamente envolvidos na criação da Rede Indígena de Memória e Museologia Social.

$\mathrm{O}$ viés qualitativo desta Tese se configurou em uma pesquisa de campo de longa duração e de caráter macro-analítico - sem perder de vista o viés etnográfico oriundo de minha experiência de pesquisa de longa duração junto aos Kanindé de Aratuba e outras experiências de museus indígenas. Dentre os principais sujeitos deste estudo, as populações indígenas que protagonizam processos museológicos no Brasil, destaco as marcantes atuações de Nino Fernandes (povo Tikuna), um dos fundadores do Museu Maguta (1991), e de José Maria Pereira dos Santos, o cacique Sotero (povo Kanindé), criador do Museu dos Kanindé de Aratuba/CE (1995) - pioneiros no que os indígenas tem denominado de uma 'museologia indígena', ao referirem-se às suas práticas, ações e experiências museológicas.

A noções de 'etnomuseografia' e 'ação museológica indígena', resultaram de um esforço analítico para o amadurecimento de uma perspectiva teórico-metodológica adequada a analisar os processos museológicos indígenas. 
Este alargamento do olhar - que acompanhou a projeção do Museu dos Kanindé no cenário nacional e a articulação que resultou na criação da Rede Indígena de Memória e Museologia Social - nos possibilitou delimitar o principal problema de pesquisa que tenho me debruçado nesta trajetória e que se evidenciaram enquanto o cerne desta tese: as relações entre memória, mobilizações étnicas e museus indígenas.

Ao invés de fixar-me em uma experiência específica, localizada numa área circunscrita ao território de um povo e/ou o estudo de caso de outro museu, os trabalhos de observação participante se constituíram a partir de dois trajetos entrecruzados: continuei seguindo os caminhos do Museu dos Kanindé e seus sujeitos, para além do Sítio Fernandes, após 2012; e analisei a sua convergência, juntamente com outras experiências museológicas, nas mobilizações dos povos que constituíram e se agregaram à Rede Indígena de Memória e Museologia Social no Brasil, antes e depois de 2014. Nesta trajetória, foram produzidas as narrativas, fatos e processos que, tornados dados da pesquisa, problematizamos e analisamos.

\section{Museus indígenas: temas e problemas}

Em 2006 iniciou-se meu envolvimento direto com os museus indígenas, a partir de uma primeira ação de pesquisa participativa junto ao povo Tapeba de Caucaia/CE, em seu Memorial Cacique Perna-de -Pau (Gomes \& Vieira Neto, 2009). Muitas experiências acumuladas deste então passaram, posteriormente, por um processo de objetificação que foi efetuado durante a análise do material empírico, a partir de 2010, que processou-se desde um olhar retrospectivo - retrospective conversion, segundo Tim Ingold (2014) (compreendendo pelo termo a reavaliação de situações de pesquisa frente aos novos problemas) - e introspectivo (questionando recorrentemente minha própria trajetória e atuação) - direcionando-se à compreensão das alteridades em questão. Como entender e contextualizar os rumos que a investigação 
tomou, com o crescente destaque e a importância cada vez maior que a mobilização que resultou na criação da Rede Indígena de Memória e Museologia Social tomou nas interações da pesquisa de campo? Segundo o antropólogo João Pacheco de Oliveira, "[...] a mudança de escala não é uma escolha do pesquisador, mas um componente da realidade etnográfica, pois faz parte das estratégias e obrigações estabelecidas pelos próprios interlocutores" (Oliveira 2013:10).

Entre 2012 e 2019, portanto, efetuamos uma rotação de perspectivas que possibilitaram novas formas de problematizar os museus indígenas. Em dezembro de 2014, nos deparamos com dinâmicas oriundas da criação desta nova instância de mobilização que agregou diferentes museus, povos e apoiadores - que foi a Rede Indígena de Memória e Museologia Social. Mesmo assim, consideramos que os caminhos empreendidos nesse estudo recém finalizado dão continuidade às análises e reflexões teórico-metodológicas sobre os museus indígenas a partir da problemática central já apontada. No entanto, um novo elemento, a cosmologia - que já estava presente no estudo de 2012 - ganhou um grande vulto nesta Tese, expressão de sua importância na pesquisa de campo que acompanhou os processos museológicos ao longo destes anos.

Seria possível pensar em uma 'epistemologia dos museus indígenas'? Quais as formas de constituição de conhecimentos que fundamentam os significados e as práticas dos indígenas em seus museus? Essas questões nos direcionaram à necessidade de compreender aspectos da cosmologia dos povos, que possuem importância fundamental em suas relações com a memória e com o passado, guiando a constituição destes espaços, processos e ações museológicas, a partir da compreensão da especificidade do que chamamos de 'memória' entre os povos indígenas.

Como os sujeitos e coletividades étnicas rearticulam suas cosmologias em relação aos diferentes contextos e relações em que os museus indígenas estão presentes? E como se relaciona a construção social da memória com as cosmologias indígenas nestas experiências 
museais? Onde se tocam as mobilizações étnicas e as dinâmicas cosmológicas? E como os museus indígenas influenciam dinamicamente nesta relação? Estas foram algumas das questões que nos propusemos a tratar no referido estudo - impostas fortemente nos trabalhos de campo etnográficos.

Para compreender as experiências museológicas indígenas, é preciso refletir sobre como estas populações organizam, nos museus, as suas ideias, percebendo como classificam a realidade para si e, ao apresentarem-se, como redimensionam, nestes processos sociais, seus conhecimentos e cosmovisões. Nessa perspectiva, os museus indígenas expressam 'formas de vida', maneiras de praticar uma infinidade de modos de classificação do mundo. São muito mais que, simplesmente, espaços físicos para a exposição de objetos, memórias e patrimônios. Nesse ponto-de-vista, a relação entre museus indígenas e cosmologias tornou-se uma problemática crucial, nos levando à formular o conceito de 'cosmopolíticas da memória'.

Acerca da noção de 'cosmopolítica', há diferentes perspectivas para seu uso, a partir de autores como Isabelle Stengers, Eduardo Viveiros de Castro e Gustavo Lins Ribeiro, entre outros, que a formularam frente a diferentes contextos e problema analíticos, evidenciando o caráter polissêmico do conceito e sua utilização para referir-se, de diferentes formas e fornecendo respostas distintas - às mudanças e dilemas na práxis antropológica atual. Bruno Latour foi um dos precursores de um debate que ganhou importância no cenário da Antropologia com a discussão presente em seu livro Jamais fomos modernos, cuja primeira edição foi publicada em 1991, na França, e em 1994, traduzido no Brasil. Em todos estes autores identificamos aspectos relevantes com os quais dialogamos, visando a sustentação teórica de nossa abordagem e formulações conceituais, hipóteses e argumentações. Cada um destes autores, que utilizam de modos distintos a noção de 'cosmopolítica', nos trazem análises interessantes sobre as transformações sociais em contextos pós-coloniais nos quais emerge uma antropologia mundial e transnacional. 
Em 1996, foi publicado o artigo 'Os pronomes cosmológicos e o perspectivismo ameríndio', de Eduardo Viveiros de Castro ${ }^{8}$; e, em 1997, Isabelle Stengers começou a publicar a série Cosmopolitiques, composta por 7 volumes. Dentre os aspectos comuns ao momento epistemológico em que a noção de 'cosmopolítica' veio tornando-se cada vez mais usual, enquanto ferramenta conceitual frente aos problemas teóricos surgidos, é Viveiros de Castro quem melhor resume o arcabouço comum, para o qual convergiram vários autores, no que veio a ser conhecido como a 'virada ontológica'. Afinal de contas, como escreve o autor, em seu livro Metafísicas Canibais:

“[...] a conclusão a que chegaram muitos antropólogos (embora por diversos outros motivos), quando argumentaram que a distinção clássica entre Natureza e Cultura - artigo primeiro da Constituição da disciplina, em que ela faz seu voto de obediência à velha matriz metafísica ocidental - não pode ser utilizada para descrever dimensões ou domínios internos a cosmologias não ocidentais sem passar antes por uma crítica etnológica rigorosa. Tal crítica, no presente caso, impunha a redistribuição dos predicados subsumidos nas duas séries paradigmáticas da 'Natureza' e da 'Cultura': universal e particular, objetivo e subjetivo, físico e moral, fato e valor, dado e instituído, necessidade e espontaneidade, imanência e transcendência, corpo e espírito, animalidade e humanidade etc" (Viveiros de Castro 2015:42, grifo e negrito nosso).

Entre as diferentes respostas a este dilema teórico e epistemológico da Antropologia, Viveiros distingue, além de sua própria abordagem, os trabalhos de Isabelle Stengers e Bruno Latour, diferenciando o trato dado por cada um deles à noção de 'cosmopolítica' e às situações em que a utilizaram. Em sua perspectiva,

"O termo reescreve equivocamente a expressão 'política cósmica', que usei para descrever o multinaturalismo perspectivista (em contraste com o multiculturalismo relativista enquanto 'política pública') em meu artigo (1996), isto é, antes de ter encontrado o conceito de cosmopolítica em Stengers (1996) 2003). Latour, por sua vez, adotou o conceito amazônico de multinaturalismo para designar a inviabilidade [...] do duo modernista multiculturalismo/mononaturalismo" (Viveiros de Castro 2015:71). 
Viveiros de Castro formulou sua noção de cosmopolítica a partir da percepção, desde suas próprias pesquisas e as de outros antropólogos, bem como em documentos e relatos históricos, de que

"A etnografia da América indígena contém um tesouro de referências a uma teoria cosmopolítica que imagina um universo povoado por diferentes tipos de agências ou agentes subjetivos, humanos como não-humanos - os deuses, os animais, os mortos, as plantas, os fenômenos meteorológicos, muitas vezes também objetos e artefatos - todos providos de um mesmo conjunto básico de disposições perceptivas, apetitivas e cognitivas, ou, em poucas palavras, de uma 'alma' semelhante" (Viveiros de Castro, 2015:43, negrito nosso).

A existência de múltiplas agências e agentes, para além dos seres humanos, bem como as características que eles possuem, que resume como correspondendo a terem uma 'alma semelhante', levou Viveiros de Castro a elaborar o perspectivismo ameríndio, enquanto uma das principais respostas teóricas da Antropologia frente às interrogações do nosso tempo. Bem diferente é a perspectiva de Gustavo Lins Ribeiro, que considera "A antropologia, desde seu começo", enquanto "uma cosmopolítica sobre alteridade de origem ocidental" (Ribeiro 2006:155). As formulações deste autor contêm importantes questões teóricas e epistemológicas sobre a natureza e as relações de poder inerentes à produção do conhecimento antropológico, as condições de constituição da antropologia como disciplina e as estruturas de poder e conflito à nível global, que configuraram uma dinâmica geopolítica disciplinar específica, que reflete as contradições do 'sistema mundial' em um capitalismo globalizado. Apesar da validade de sua perspectiva, nos distanciamentos da abordagem de Ribeiro sobre a antropologia como cosmopolítica (Gomes 2019:163-166).

As dinâmicas étnicas envoltas às cosmopolíticas da memória ocorrem por meio da construção de narrativas da resistência, materializadas em histórias que expressam a maneira como essas populações recriaram os sentidos da sua própria historicidade e reinventaram suas culturas, contando as suas trajetórias e existências no tempo: atuali- 
zando a cada geração o significado, a poética e a política voltadas aos processos de rememoração enquanto ato de re-existir continuamente. Deste ponto de vista, ao mesmo tempo em que essas populações não precisaram de uma instituição em especial para construírem suas políticas da memória, nos museus indígenas o papel das cosmologias assume uma dimensão central enquanto mediador, uma espécie de 'filtro', do processo de sua tradução para a ótica de cada povo (Gomes 2019:173-174).

Uma compreensão cosmopolítica da memória nos revela que nos processos de transmissão e aprendizagem que ocorrem nos museus indígenas, muitas vezes a preservação física não necessariamente significa a conservação da dimensão material das coisas. $\mathrm{O}$ processo de transmissão pode, muitas vezes, ter sentido, até mesmo, no ato de destruição da materialidade. Isso nos direcionou à reavaliação de uma concepção tradicional do que seja a salvaguarda dessas memórias a partir da preservação de seus suportes físicos. Mais amplamente, a relação de indígenas e espíritos, aos quais muitos chamam de Encantados, nos processos de rememoração que ocorrem nos museus indígenas que acompanhamos, evidenciaram outras concepções e usos sociais da memória, constituídas a partir da interação com estes sujeitos não -humanos que possuem um papel preponderante na forma com que estas populações se relacionam com o passado e como o significam no presente. Afinal, uma íntima relação com o passado torna-se possível por meio do contato e comunicação direta com os Encantados, que se dá por meio da esfera ritualística ou no cotidiano (Gomes 2019:174).

A análise antropológica sobre a agência de sujeitos não-humanos (lugares, bichos ou coisas, por exemplo) possui um papel central no debate epistemológico atual, subsidiando muitas pesquisas que questionam o universalismo da dualidade 'natureza' e 'cultura', a partir da sua confrontação empírica, através de pesquisas de campo, com outras concepções de humano, pessoa, objetos e agência, bem como aos seus dualismos associados (noções de natural/sobrenatural, materialidade/imaterialidade e vida/morte, por exemplo). Em nosso caso, 
além de uma percepção etnográfica sobre os significados semânticos de memórias e objetos (Gomes 2016), nos deparamos com a agência dos Encantados nos museus indígenas e nas interações que conformaram a Rede Indígena de Memória e Museologia Social. Esta percepção teve momentos privilegiados nos três fóruns de museus indígenas. O fato de não estar 'vivo', nestes casos, não foram impeditivos para a agência social e a relação com as pessoas. Estar 'morto', ou melhor, 'Encantado', possibilitou participar do processo social e interferir no rumo dos acontecimentos. Estar 'Encantado' tornou-se uma condição que permitiu que estes seres fossem percebidos no horizonte semântico dos demais sujeitos com quem se comunicam de várias maneiras, motivando (re)ações e constituindo sentidos para os processos museológicos, de acordo com cosmovisões nas quais estes espíritos possuem papéis e posições centrais em suas relações com as pessoas, interferindo nos planos terreno e material das relações sociais (Gomes 2019:178-179).

Cosmopolítica da memória é uma noção em construção. Vem sendo articulada, desde alguns destes pressupostos apresentados, por meio das palavras e atitudes dos próprios indígenas, frente às situações concretas e reais, nas quais percebemos que se dá a ativação de processos de rememoração, de ressignificação do passado e de construção da memória que aconteceram nas interações entre diferentes sujeitos e grupos sociais, humanos e não-humanos de diferentes matizes, envolvidos nas atividades dos museus indígenas. São tantos sujeitos quanto agências e agenciamentos (Gomes 2019:183).

O foco deste estudo não é de natureza eminentemente teórica: possui forte conteúdo etnográfico. No entanto, nos preocupamos tenazmente com a formulação de conceitos adequados à realidade empírica evidenciada em nossas pesquisas de campo. Quando o inesperado nos afeta em meio ao desenrolar dos acontecimentos que consideramos como parte de uma investigação, escolher dentre alguns caminhos torna-se necessário. E isso geralmente acontece, principalmente quando tratamos de pesquisas de longa duração. É necessário 
optar: ou desconsideramos àquilo que nos escapa à compreensão (e previsão) ou rearticulamos nossa visão frente aos novos fatos, processos e sujeitos que se impõem à revelia de nossa vontade - como parte das relações sociais que compõem a trajetória de uma pesquisa. Optamos pela segunda opção, que se mostrou um caminho mais árduo e caudaloso, porém, muito mais instigante e relevante do ponto de vista teórico-analítico e etnográfico-descritivo.

As principais noções operacionalizadas na investigação que resultou em nossa Tese de Doutorado foram as de 'cosmopolítica da memória', 'etnomuseografia', 'ação museológica indígena', 'apropriação' e 'tradução', constituídas enquanto terminologias aptas à compreensão antropológica dos museus indígenas. A análise apresentada, bem como as experiências empíricas que resultaram na construção destes conceitos, partiram da etnografia efetuada desde nossa experiência particular, em que as problemáticas da reflexividade e da autorepresentação colocaram-se como pontos cruciais para uma abordagem relacional e situacional das experiências dos indígenas com seus museus. Ao longo de todo o estudo, fundamentamos estas noções, manejando-as enquanto categorias analíticas para o entendimento de diferentes situações empíricas e de problemas que compuseram os caminhos da investigação.

Para além mesmo da identificação de categorias nativas, exercício salutar extremamente útil para uma antropologia dos museus indígenas, é necessário também analisar como ocorre a apropriação e a tradução de categorias externas para a realidade dos povos nos processos museológicos. É preciso compreender como ocorre, nessa variação semântica provinda do uso e das práticas, conforme nos ensinou Marshal Sahlins (1997a, 1997b, 2003, 2008), a sua transformação, de noções exteriores, em termos nativos. Identificamos e analisamos estes trajetos de composições de sentidos. Foi possível, no caso do povo Kanindé - sujeitos e protagonistas de nosso estudo de 2012 perceber como algumas categorias exteriores, relativas aos discursos e práticas sobre museus e patrimônios, foram apropriadas muito rápida e dinamicamente através de diversos processos de tradução e, signifi- 
cadas segundo suas perspectivas, apreendidas localmente e acionadas nas relações internas e externas estabelecidas em diversas situações. Transformaram-se em noções com atribuições e sentidos que promoveram novas associações e significados, que se diferenciavam tenazmente daqueles onde eles as apreenderam.

Esta antropologia dos museus indígenas visa perceber as mudanças semânticas processadas a partir das interações sociais, entre estruturas e história, nos moldes propostos por Marshall Sahlins e em diálogo com as proposições de Ulf Hannerz (1997) e Fredrik Barth (1998 e 2000). É importante analisar como categorias externas se 'indigenizam' e, especialmente, como isso acontece, processualmente, no caso dos museus indígenas: como estes processos se interseccionam entre as escalas macro e micro-locais, nas quais interagem os sujeitos sociais? Acompanhando os processos museológicos indígenas, conseguimos identificar fluxos de informações, de saberes, de pessoas, de objetos e de práticas sociais, que podem ser melhor percebidos através de análises simultaneamente sincrônicas e diacrônicas, sociológicas e microanalíticas, nas quais os dados documentais são cruzados à experiência etnográfica, em uma observação participante contínua e de longa duração.

Como analisar a constituição dos museus indígenas - considerando as práticas sociais dos povos - e, não necessariamente, apenas as representações efetuadas por meio de seus discursos? A noção de 'ação museológica indígena', nos auxiliou deveras na compreensão de como ocorre a agência de sujeitos indígenas ao construírem seus próprios museus, de acordo com suas categorias e da maneira como, nestes processos museológicos, apresentam-se através da atribuição de sentidos específicos às suas memórias, objetos, referências de pertencimento e cosmologias em transformação.

Ao longo de nosso estudo, há também um recorrente diálogo entre representantes de povos e museus indígenas com o Estado brasileiro. Entretanto, para além das políticas públicas, as políticas étnicas são postas em prática nestes embates com o Estado e seus gestores. Se, 
por um lado, é importante pensar no modo como as políticas públicas se relacionam com os museus indígenas, por outro, vale destacar que a memória é uma eficiente ferramenta de resistência articulada no horizonte das mobilizações étnicas como parte das estratégias de luta dos povos - independente da existência de museus e, até mesmo, para além do Estado. Várias das experiências presentes naquele estudo já existiam antes e para além de sua relação com o Estado. Muitas vezes, em oposição a ele. Qual seria o estatuto da memória entre os diferentes povos indígenas?

Em nosso entendimento, há três questões centrais, que são gerais e estruturantes, na análise que empreendemos sobre os museus indígenas: o debate sobre autonomia; a relação com a cosmologia/ espiritualidade; e a associação com as mobilizações étnicas. A relação com o Estado e o debate sobre políticas públicas museológicas e culturais constituiu um importante contexto macro no qual os processos narrados aconteceram e estão situados temporalmente. Qual a importância da esfera econômica e da necessidade de recursos financeiros destas experiências museológicas indígenas, que também se referem às políticas públicas para financiamento e, de maneira mais ampla, à própria sustentabilidade destes processos? E qual a relação disso com a autonomia?

Articular os diálogos com o Estado - as 'coisas do governo', no dizer do cacique Sotero, sem perder de vista a agência indígena, significa tentar perceber essa relação de acordo com o modo como ela é interpretada pelos próprios sujeitos integrantes dos grupos étnicos. Essa é uma outra questão central: como os indígenas compreendem seus processos museológicos? Como registrar e entender as várias visões dos processos? Em busca dessa compreensão, a articulação dos níveis de análise é fundamental: étnico-local, estadual e regional; nacional e internacional; interrelacionados e interagindo. Estes vários níveis de interação são também as diferentes escalas onde se dão as ressignificações e sentidos atribuídos aos processos museológicos, pelos indivíduos, povos e coletividades. 
Qual seria a importância e o impacto desta pesquisa antropológica na realidade do povo Kanindé? Essa foi uma questão inevitável de deparar-me. Como a relação com os Kanindé moldou o pesquisador que me tornei, durante os 10 anos de investigação desenvolvida junto com eles? Tentar responder estes questionamentos nos direcionou ao difícil desafio de entender as apropriações que eles próprios fizeram, neste período, sobre minha (?) pesquisa, seu museu e os aspectos de sua memória social e patrimônio - dialogando com minha análise antropológica. Minha?! De fato, fui moldado por eles, influenciado fortemente pela visão de museu do cacique Sotero e à forma magistral como articulou as memórias sociais de seu povo à mobilização por reconhecimento étnico, por via de um saber-fazer museal radical, indígena e comunitário. Mas até que ponto eles também se moldaram nessa relação conosco? É difícil mensurar. Fui o primeiro antropólogo a efetuar trabalho de campo de longa duração no Sítio Fernandes.

$\mathrm{Se}$ as trocas oriundas de um contexto de pesquisa colaborativa são uma via de mão-dupla e desdobram-se em várias direções, sem um rumo linear ou pré-determinado, assumo que minha formação como antropólogo se deu através da relação com os Kanindé. Isso, tanto por conta da importância que a investigação tomou entre eles (menos no sentido estritamente acadêmico, e mais, no de ter potencializado a ação museológica indígena e uma maior apropriação coletiva do museu no horizonte da população, por exemplo), quanto pela importância que eles tiveram em meus caminhos como pesquisador. Esta experiência, portanto, foi apresentada em nossa Tese por meio de um duplo trajeto: de conectar-me aos Kanindé, que a mim se associam para nos transformarmos juntos e nos relacionarmos com e em outros contextos. Esta influência - econfluência - recíproca teve sua iniciação nos dois primeiros anos de convivência mais intensa, no Sítio Fernandes, entre 2010 e 2012, na pesquisa de campo do mestrado.

As problemáticas que seguiram-se desenvolvendo ao longo dos anos, se delineando e se aprofundando em meu horizonte analítico, foram inicialmente sistematizadas em 2012, como hipóteses oriun- 
das de problemas de pesquisa vislumbrados desde uma perspectiva etnográfica. Havia avançado um pouco, ao efetuar um estudo de caso de um museu indígena particular, oriundo de um contexto em que estivera associado, desde seu início, a um processo de mobilização por reconhecimento étnico, situação privilegiada, portanto, para realizar um estudo sobre etnicidade e entender como se processa a organização social das diferenças na interface da relação entre museu, memória e etnicidade .

A antropologia dos museus indígenas aqui proposta é também parte de uma antropologia reflexiva. Nesse sentido, uma outra problemática tornou-se inevitável: como analisar estas experiências, nas quais eu próprio auxiliei para sua constituição?!

"It is now taken for granted that a good ethnography should be 'reflexive'. But what exactly does that mean? Most basically, reflexivity describes the capacity of any system of signification, including a human being - an anthropologist - to turn back upon or to mirror itself" (Robertson 2002:785-792).

Mas qual o sujeito que não participa da construção de uma realidade social quando passa a vivenciá-la - independentemente do olhar e do fazer antropológico? O questionamento sobre a reflexividade perpassa todos os capítulos de nossos estudos sobre os museus indígenas. Estamos analisando processos em que estamos profundamente envolvidos - inclusive para muito além do âmbito acadêmico, como investigador - no que pode ser considerado parte de uma 'pesquisa-ação', participativa e colaborativa9. Qual o caráter dos dados, informações e conhecimentos construídos em processos colaborativos de pesquisa? Não seriam em regime de co-autoria? Mas, qual pesquisa (especialmente a antropológica) não é feita em co-laboração (entendida como um trabalho em conjunto)? Como entender, nesse horizonte, as apropriações feitas pelos indígenas de termos e categorias utilizadas em nossos estudos antropológicos sobre eles e nas múltiplas interações situadas em diferentes contextos? Como eles compreendem os nossos estudos? Ou seria mais apropriado redimensionar as noções de eles 
e nós?! Quem são eles e quem é o nós? Na medida em que partem as populações indígenas - nessa compreensão sobre o pesquisador - de suas próprias realidades e narrativas, evidenciadas e analisadas por procedimentos teórico-metodológicos da Antropologia, nos questionamos: de quem seria a autoria do texto oriundo de etnografias, a partir do momento em que é produzido no contexto de uma realidade específica e retorna a ela, sob a forma de apropriação? Não visamos responder estas questões, mas evidenciá-las como aspectos centrais para uma compreensão dos museus indígenas do ponto de vista antropológico.

Com a reflexão contínua e sistemática sobre os museus indígenas, seguida da análise de um volumoso material empírico, feita com a conclusão da Tese em 2019, apuramos nosso olhar para seguirmos refletindo que:

"Understanding an ethnography begins with the recognition that it involves interpretation. Ethnographies do not merely depict the object of anthropological research, whether a people, a culture or a society. Rather an ethnographic account constitutes the researcher's interpretation of what he or she has observed and/or heard" (Jacobson 1991:3).

Como interpretar os museus indígenas? Como compreender este museu, que é constituído declaradamente como um discurso em primeira pessoa? Diferentemente do museu etnográfico que, embora fale muitas vezes muito mais sobre a sociedade que o constituiu, mantém seu discurso ancorado em um olhar que define como e o que é o 'outro': o (re)apresenta. Mas quem e o que seria o 'outro' do 'outro', nos museus indígenas? Segundo Eduardo Viveiros de Castro :

“[...] a despeito de uma igual ignorância a respeito do outro, o outro do Outro não era exatamente o mesmo que o outro do Mesmo. Talvez coubesse mesmo dizer que era seu exato oposto, não fosse o fato de que, nos mundos indígenas, a relação entre estes dois outros da humanidade, a animalidade e a divindade, é completamente outra daquela que herdamos do cristianismo" (Viveiros de Castro 2015:36). 
Seria este museu, dos indígenas, como quase todas as abordagens reforçam (e que seus discursos geralmente confirma), um museu 'pronominal', em primeira pessoa? Ou, um museu 'em perspectiva', que possui posição e pontos de vistas definidos somente em e desde cada relação? E em que medida estas experiências são de 'autorrepresentação’, ou seja, voltadas para si mesmas? Não poderiam ser pensadas também como experiências de 'alter-representação', ou seja, voltadas aos 'outros' dos indígenas que os organizam? Não seriam, antes de tudo, os museus indígenas, experiências de auto-identificação?! Nestes processos, são selecionadas imagens, objetos e referências de pertencimento sobre um sujeito coletivo (um 'nós'), que estão em diálogo com outros sujeitos - constituindo 'fronteiras' e 'limites' para as interações - nas apresentações que fazem de si (Hannerz 1997). Mas, mesmo sendo uma representação de si, para quem é voltada esta apresentação? Para si mesmo (pessoas e coletivos)? Para o(s) outro(s) (indivíduos e sociedade circundante)?! De um lado, também fazem parte de um processo de autoconvencimento: somos indígenas (especialmente em contextos de afirmação étnica); por outro, de alter-convencimento: vejam como somos indígenas!!

Em verdade, os museus indígenas podem ser considerados como 'zonas de contato', no sentido dado por James Clifford, que toma de empréstimo o termo de Mary Louise Pratt, que o define enquanto "espaço de encontros coloniais, o espaço onde povos geográfica e historicamente separados entram em contato uns com os outros e estabelecem relações concretas, geralmente envolvendo condições de coerção, desigualdades radicais e conflitos irredutíveis" (apud Clifford 2016:5). Mas os 'museus indígenas' seriam zonas de contatos, na perspectiva de um 'encontro colonial'? Segundo James Clifford,

“[...] a expressão 'zona de contato' é uma tentativa de invocar a co -presença espacial e temporal de sujeitos anteriormente separados por disjunções geográficas e históricas, e cujas trajetórias agora se cruzam. Ao usar o termo 'contato' pretendo enfatizar as dimensões interativas, improvisadas, dos encontros coloniais, tão facilmente ignoradas ou suprimidas pelos relatos difusionistas de conquistas 
e dominações. Uma perspectiva de 'contato' destaca como os sujeitos são constituídos e as relações que têm uns com os outros. Ela enfatiza a co-presença, a interação, interrelacionando entendimentos e práticas, muitas vezes dentro de relações de poder radicalmente assimétricas. Quando os museus são vistos como zonas de contato, sua estrutura organizacional enquanto coleção se torna uma relação atual, política e moral concreta - um conjunto de trocas carregadas de poder, com pressões e concessões de lado a lado" (Clifford 2016:5).

Seriam os museus indígenas, a 'zona de contato' de encontros pós-coloniais?! Formam 'onas de contato', de fato, o são - no entanto, de contatos conflituosos e prenhes de negociações. É preciso ir além, descrever, diferenciar, e nos propomos a isso: avançar no detalhamento do modo ocorrem estes encontros nos museus indígenas. Qual seriam, portanto, as especificidades das diferentes experiências indígenas com o que chamamos de 'museus'? Nessa trama reflexiva sobre relações de alteridade, os processos museológicos indígenas dialogam ativamente - e reelaboram-se - com a própria forma como a sociedade nacional os cobra e espera que se apresentem (e/ou sejam apresentados), em visões preconcebidas que partem de ideologias nacionais, de estereótipos e, também, de múltiplos preconceitos que se (e nos) distanciam, muitas vezes assustadoramente, do que estes sujeitos são em suas realidades, de suas formas de vida e nos complexos modos de apresentarem-se.

Uma inspiração a motivar a busca constante de um rigor analítico, conceitual e teórico metodológico para nossa Tese foi o livro Reading Ethnography, de David Jacobson (1991). Ao destrinchar a construção textual da argumentação e análise de algumas das principais escolas teóricas do pensamento antropológico ao longo do século XX, o autor nos conduz por leituras epistemológicas de obras clássicas. Jacobson sugere que as abordagens que priorizam modos de pensamento possuem as evidências linguísticas como dados prioritários, enquanto as abordagens que priorizam modos de ação utilizam-se, no mais das vezes, de evidências comportamentais. 
"Ethnographic arguments consist of claims (conclusions, assertions, propositions, explanations, interpretations) about people's behavior (or about a culture or a society) and data (grounds, facts) that constitute evidence for or against them. An ethnography has a point of view, and it includes and excludes data in terms of their relevance to that point of view" (Jacobson 1991:8).

Uma questão crucial se coloca: priorizar a análise das representações e discursos ou das ações que os indígenas empreendem para a constituição de seus museus? Ao realizar uma avaliação crítica de tendências teóricas na Antropologia do século XX, baseando-se em Raimond Firth, Jacobson diferencia seus níveis de análise entre as que priorizam os 'modos de pensamento' (modes of thought) e as que adotam como foco analítico os 'modos de ação' (modes of action). Outros antropólogos designaram estas diferentes abordagens, clássicas na história do pensamento antropológico, sob outros termos, como: teoria/prática; estrutura/processo; agência/estrutura; cultura/estrutura social; individualismo metodológico/coletivismo metodológico. Pesquisadores que priorizaram os 'modos de pensamento' preocuparam-se em analisar sistemas de ideias e noções que orientam as ações, fornecendo modelos para a construção dos sentidos sobre as próprias ações e as dos outros.

Os que privilegiaram como foco os 'modos de ação' direcionaram suas análises para os comportamentos de indivíduos nas situações sociais e sua relação com as ideias, ou seja, preocupam-se com o que as pessoas fazem na prática. Cada uma dessas abordagens, para Dave Jacobson, utilizam diferentes tipos de dados como evidências e sistematizam de um modo distinto a relação entre suas hipóteses e os argumentos que lhes dão sustentação, em uma determinada organização textual e narrativa (Jacobson 1991:9-15).

Privilegiamos a perspectiva de um 'individualismo metodológico' - termo pelo qual ficaram conhecidas as abordagens antropológicas que enfatizam analiticamente a ação dos atores sociais, ou seja, a agência dos indivíduos no rumo dos acontecimentos. Esta longeva e profí- 
cua tradição de estudos sociais - que privilegia a ação dos indivíduos e que pode ser remontada à sociologia clássica de Max Weber - tem em Fredrik Barth a mais forte influência nas abordagens antropológicas para a etnicidade, afirmando a importância destas cultivarem um caráter interacionista, situacional e processualista. Nessa direção, a subjetividade é um forte componente a ser considerado em se tratando de compreender a visão que os indivíduos possuem sobre os processos sociais que protagonizam.

Embora a tipologia proposta por David Jacobson seja útil para classificação do processo de construção dos argumentos que embasam análises e teorias antropológicas, no processo de interpretação de dados como evidências é muito difícil para o antropólogo que elabora argumentos para uma hipótese dividir intencionalmente o nível de análise que prioriza dos tipos de evidências que apresenta, como garantias para a validade de sua argumentação/interpretação (Jacobson 1991:12-16). Nesse sentido, uma análise rigorosa busca associar "[...] the level of analysis or the sort of social reality an ethnography depicts" com o "use of different kinds of data, and different kinds of data warrant different kinds of claims and/or conclusions" (Jacobson 1991:10). O antropólogo nos chama atenção de que é preciso "[...] identifying an ethnography's claims and evaluating them with reference to the data presented in support of them" (Jacobson 1991:8). Continua, afirmando que:

"[...] the anthopologist's interpretation determines his or her selection of fieldwork observations for inclusion in an ethnographic account. The selection and presentation a not simply a record of observations made during the anthropologist's fieldwork" (Jacobson 1991:7).

Praticamos uma antropologia que prioriza o estudo da agência, mas que não desconsidera, para melhor compreender as ações em suas motivações, como estão significando e agindo sobre os museus os sujeitos indígenas que protagonizam estes processos. Essas perspectivas foram atualizadas na antropologia por várias abordagens co- 
nhecidas como estando vinculadas à uma "teoria da prática" (Ortner 2011:439-455). Segundo Sherry Ortner,

"Nos últimos anos, tem havido um crescente interesse em análises centradas em algum termo de um grupo de termos inter-relacionados, a saber: prática, práxis, ação, interação, atividade, experiência, performance. Um segundo grupo de termos, muito próximos àqueles, coloca o enfoque sobre quem realiza as ações: agente, ator, pessoa, self, indivíduo, sujeito" (Ortner 2011:440).

Aos nos deparamos, desde essa perspectiva, com o modo como os museus indígenas são significados nas mobilizações étnicas, percebemos que:

"A dimensão que adquire a ação política em âmbitos dessa natureza constitui um campo assinalado por ambiguidades e contradições, na medida em que se manifesta como confrontação entre lógicas culturais e estruturas de sentido que o subsistema dominante costuma mostrar como irreconciliáveis para conseguir se reproduzir" (Bartolomé 2017:49).

Os processos sociais nos quais a ação política dos museus indígenas acontece propicia que ocorram conjuntos polissêmicos de interações dinâmicas. Não compreendemos estas trocas e fluxos culturais - dialogando com Ulf Hannerz (1997) - como a passagem de algo de um local a outro, estaticamente. Buscamos perceber as diversas sobreposições e os contatos permanentes, em/entre diferentes níveis e contextos de interação e em/entre situações ocorridas em vários locais, protagonizadas por diversos sujeitos ao mesmo tempo. Segundo o antropólogo sueco,

"Fluxo, mobilidade, recombinação e emergência tornaram-se temas favoritos à medida que a globalização e a transnacionalidade passaram a fornecer os contextos para nossa reflexão sobre a cultura. Hoje procuramos locais para testar nossas teorias onde pelo menos alguns dos seus habitantes são crioulos, cosmopolitas ou cyborgs, onde as comunidades são diásporas e as fronteiras na realidade não imobilizam mas, curiosamente, são atravessadas. Freqüentemente é nas regiões fronteiriças que as coisas acontecem, e hibridez e colagem são algumas de nossas expressões preferidas por identificar qualidades nas pessoas e em suas produções" (Hannerz 1997:7-8). 
O envolvimento de longa duração com os processos museológicos indígenas fomentou a construção e o amadurecimento de um quadro teórico e de uma reflexão metodológica que fundamentam nossa abordagem analítica interdisciplinar, marcadamente antropológica, em diálogo com questões relacionadas aos estudos sobre etnicidade, memória e patrimônio cultural.

Segundo o antropólogo argentino radicado no Estado de Oaxaca, sul do México, Miguel Bartolomé, referindo-se ao estudo do pluralismo cultural na América Latina,

"O desafio para uma antropologia contemporânea das relações interétnicas, dos fluxos e dos cruzamentos interculturais, radica em aproximar-se ao presente através de termos analíticos similares, tratando de descobrir mais as conexões do que as distâncias entre os sistemas culturais, enfatizar mais as dinâmicas que as permanências. Contudo, isso não implica excluir artificialmente as distâncias, as diferenças e as possíveis irredutibilidades; ou seja, tudo aquilo que faz um grupo humano ser o que ele é e o que propõe - e defende como sua alteridade" (Bartolomé 2017:52).

A problematização sobre os museus indígenas é uma chave de acesso à compreensão dos processos de mobilização étnico-política dos povos indígenas hoje no Brasil, na América Latina e nos mais diversos continentes, já que fazem parte de processos sociais de escala global. Como repensar a etnografia no contexto de uma antropologia reflexiva? Além de questionar minha própria participação na realidade estudada, juntamente com a busca constante de uma maior simetria e horizontalidade nas relações de pesquisa, foi tornandose cada vez mais necessário problematizar o caráter colaborativo do conhecimento produzido, como resultante de um diálogo que origina, de fato, um processo de co-autoria. Como expressar esse caráter dialógico, interativo e colaborativo através de uma produção textual autoral? De quem (e o quê) seriam os dados da pesquisa de campo e a análise empreendida?

Os museus indígenas constituem e processos sociais e étnicos dinâmicos e multifacetados, experiências privilegiadas para analisar 
como se constroem e ressignificam as memórias e os discursos sobre 'patrimônios' e 'cultura' - não no sentido meramente instrumental/ utilitário - mas em suas apropriações e traduções para realidades específicas e de acordo com epistemologias que expressam formas de conhecimentos próprias, a partir das quais seus protagonistas interagem em embates sociais oriundos de relações de conflito, poder e disputa.

\section{Notas:}

1 A Tese de Doutorado Museus indígenas, mobilizações étnicas e cosmopoliticas da memória: um estudo antropológico, sob orientação do prof.Dr. Renato Monteiro Athias, foi apresentada no dia 28 de fevereiro de 2019 ao Programa de Pós-Graduação em Antropologia da Universidade Federal de Pernambuco.

2 Em nossa pesquisa de doutoramento, a opção a favor de uma observação etnográfica na escala micro-local se deu concomitantemente à ideia de realização de trabalhos de campo em múltiplos locais. Costuma-se chamar essa perspectiva de 'multissituada'. Um antropólogo associado à esta noção é George Marcus (Ethnography in/of the World System: the emergence of multi-sited ethnography, de 1995), um dos autores que contribuíram para a popularização desta expressão e, uma das maiores referências na definição desta modalidade de pesquisa de campo. Segundo ele, comparando as práticas de pesquisa etnográficas, afirmava há vinte anos atrás (de quando ele escreveu), que "The other, much less commom mode of ethnographic researche of consciously embedded in a world system, now often associated with the wave of intellectual capital labeled postmodern, moves out from the single sites and local situations of convencional ethonographic researche designs to examinate the circulation of cultural meanings, objetcts and identities in difuse time-space. This mode defines for itself an object of study that cannot accounted for ethnographically by remaining focused on a single site of intensive investigation” (Marcus 1995:96-97).

3 Esta pesquisa resultou na dissertação intitulada Aquilo é uma coisa de indio: objetos, memória e etnicidade entre os Kanindé do Ceará, que foi vencedora do Concurso Brasileiro da Associação Nacional de Pós-Graduação e Pesquisa em Ciências Sociais (ANPOCS) de Obras Científicas e Teses Universitárias em Ciências Sociais - Edição 2013, na categoria Menção Honrosa em Ciências Sociais (Antropologia). Em 2018, em edição datada de 2016, uma versão atualizada foi publicada como ebook, pela Editora Universitária da UFPE, sob o título: Aquilo é uma coisa de indio: objetos, memória e etnicidade no Museu dos Kanindé-CE (Gomes 2016).

4 Por duas oportunidades: entre 2011 e 2013 e, atualmente, entre 2018 e 2020. 5 Entre 2015 e 2017.

6 A realização do estágio do doutorado-sandwich no exterior foi efetuada com o apoio do Programa de Doutorado Sandwich no Exterior (PDSE), da CAPES, Brasil 
(Processo Número 88881.132320/2016-01), durante os meses de abril e agosto de 2017. Neste período, estive vinculado, na condição de Estudiante-Huésped, ao Programa de PosGrado em Antropología Social do Centro de Investigación y Estudios Superiores em Antropología Social, Unidad Pacifico Sur, sediada na cidade de Oaxaca de Juaréz.

7 O documentário intitulado Proyecto Nuestra Visión del Cambio, produzido pela UMCO em 2016, narra como surgiu, os objetivos e alguns resultados deste projeto, com testemunhos de seus integrantes e assessores. (www.youtube.com/watch?$\mathrm{v}=\mathrm{hiRdmQfOFF} \& \& \mathrm{t}=7 \mathrm{~s}$; acesso em 09/05/2019).

8 Segundo o resumo do artigo: "Este trabalho discute o significado do 'perspectivismo' ameríndio: as idéias, presentes nas cosmologias amazônicas, a respeito do modo como humanos, animais e espíritos vêem-se a si mesmos e aos outros seres do mundo. Essas idéias sugerem uma possibilidade de redefinição relacional das categorias clássicas de 'natureza', 'cultura' e 'sobrenatureza' a partir do conceito de perspectiva ou ponto de vista. Em particular, argumenta-se que a antinomia entre duas caracterizações do pensamento indigena: de um lado, o 'etnocentrismo', que negaria os predicados da humanidade aos humanos de outros grupos; de outro, o 'animismo', que os estenderia a seres de outras espécies, pode ser resolvida se se considerar a diferença entre os aspectos espirituais e corporais dos seres (Viveiros de Castro 1996).

9 Entre especialistas, considera-se como um dos pioneiros no uso e conceituação da noção de pesquisa-ação Kurt Lewin, que realizou estudos organizacionais e educacionais nos EUA do pós-guerra (Toledo \& Jacobi 2013:157). Segundo Toledo \& Jacobi, "Metodologias de pesquisa de caráter participativo ganham repercussão mundial tanto na área científica como no campo político, a partir do Primeiro Simpósio Mundial sobre Pesquisa Participante, realizado em Cartagena, Colômbia, em 1977 (Fals Borda 1986), e fundamentam-se na preocupação de garantir a participação ativa dos grupos sociais no processo de tomada de decisões sobre assuntos que Ihes dizem respeito, com vistas à transformação social, não se tratando, portanto, de uma simples consulta popular, mas sim do envolvimento dos sujeitos da pesquisa em um processo de reflexão, análise da realidade, produção de conhecimentos e enfrentamento dos problemas" (Toledo \& Jacobi 2013:156).

\section{Referências:}

BARTH, Fredrik. 2000. "Enduring and emerging issues in the analysis of ethnicity". In VERMEULEN, H. \& GOVERS, C. (eds.): The anthopology of ethnicity. Beyond ethnic groups and boundaries, pp.11-32. Amsterdam: Het Spinius.

BARTH, F., POUTIGNAT, P. \& STREIFF-FENART, J. 1998. Teorias da etnicidade seguido de grupos étnicos e suas fronteiras. São Paulo: UNESP.

BARTOLOMÉ, Miguel A. 2017. Processos Interculturais: antropologia do pluralismo cultural na américa Latina. Recife: Editora da UFPE 
CLIFFORD, James. 2016. "Museus como zona de contato". Revista Periódico Permanente, (6):1-37.

2009. "Museologia e contra-história: viagens pela costa noroeste dos Estados Unidos”. In ABREU, R. \& CHAGAS, M. (eds.): Memória e patrimônio. Ensaios contemporâneos, pp. 254-302. Rio de Janeiro: Lamparina.

FREIRE, José R. B. 1998. “A descoberta dos museus pelos índios”. Cadernos de etnomuseologia, 1:5-29.

GOMES, A. O. \& VIEIRA NETO, J. P. 2009. Museus e memória indígena no Ceará: uma proposta em construção. Fortaleza: Museu do Ceará.

GOMES, Alexandre O. 2012. Aquilo é uma coisa de indio: objetos, memória e etnicidade entre os Kanindé do Ceará. Dissertação de Mestrado. Recife: Universidade Federal de Pernambuco.

. 2016. Aquilo é uma coisa de índio: objetos, memória e etnicidade no Museu dos Kanindé de Aratuba/CE. 2016. Recife: Editora da UFPE (Série Etnicidade).

. 2016b. "Por uma antropologia dos museus indígenas: experiências museológicas e reflexões etnográficas”. In CURY, M. X. (ed.): Museus e indigenas: saberes e ética, novos paradigmas em debate, pp. 133-155. São Paulo: Secretaria da Cultura/ACAM Portinari/MAE-USP.

.2016c. "'O passado vai tá sempre na frente do presente': museus indígenas em rede, etnografia em processo”. In CURY, M. X. (ed.): Direitos indigenas no Museu: novos procedimentos para uma nova politica: a gestão de acervos em discussão, pp. 195-217. São Paulo: Secretaria da Cultura/ ACAM Portinari/MAE-USP.

. 2019. Museus indígenas, mobilizações étnicas e cosmopolíticas da memória: um estudo antropológico. Tese de Doutorado. Recife: Universidade Federal de Pernambuco.

GONCCALVES, José R. S. 2007. Antropologia dos objetos. Coleções, Museus, Patrimônios. Rio de Janeiro: IBRAM/MINC (Coleção Museu, Memória e Cidadania).

HANNERZ, Ulf. 1997. "Fluxos, fronteiras, híbridos. Palavras-chave da antropologia transnacional”. Mana, 3(1):7-39.

INGOLD, Tim. 2014. "That's enough about ethnography!". Hau: Journal of Ethnographic Theory, 4(1):383-395.

JACOBSON, David. Reading Ethnography. 1991. New York: State University of New York Press.

KOPENAWA, D. \& ALBERT, B.. 2015. A queda do céu: Palavras de um xamã yanomami. São Paulo: Campanhia das Letras.

MARCUS, George. 1995. Ethnography in/ of the World System: the emergence of multisited ethnography. (https://edisciplinas.usp.br/pluginfile.php/1897105/mod_ resource/content/1/George\%20Marcus_Etnography\%20in\%20off\%20 world.pdf; acesso em: 16/11/2019). 
MENESES, Ulpiano T. B. 1993. "A problemática da identidade cultural no museu: de objetivo (da ação) a objeto (do conhecimento)”. Anais do Museu Paulista, 1:207-222.

OLIVEIRA, João Pacheco de. 2013. "Prefácio - Índios e sertanejos, praiás e penitentes”. MURA, Claudia. 'Todo mistério tem dono'. Ritual, política e tradição de conhecimento entre os Pankararu. Rio de Janeiro: Contra Capa.

ORTNER, Sherry. 2011. “Teoria na Antropologia desde os anos 60”. Mana, 17(2):419-466.

RIBEIRO, Gustavo Lins. 2006. "Antropologias Mundiais: Para um novo cenário global na antropologia”. Revista Brasileira de Ciências Sociais, 21(60):147-185.

ROBERTSON, Jennifer. 2002. "Reflexivity redux: a pithy polemic on 'positionality". Anthropological Quarterly, 75(4):785-792.

ROCA, Andrea. 2015a. "Acerca dos processos de indigenização dos museus: uma análise comparativa". Mana, 21(1):123-155.

. 2015b. Museus Indígenas na Costa Noroeste do Canadá e dos Estados Unidos: colaboração, colecionamento e autorrepresentação. Revista de Antropologia, 58 (2): 117-142.

SAHLINS, Marshall. 2003. Ilhas de História. Rio de Janeiro: Jorge Zahar Editor. 2008. Metáforas históricas e realidades míticas. Rio de Janeiro: Jorge Zahar Editor.

. 1997a. "O 'pessimismo sentimental' e a experiência etnográfica: por que a cultura não é um 'objeto' em via de extinção (parte I)”. Mana, 1(3):103-150. . 1997b. "O 'pessimismo sentimental' e a experiência etnográfica: por que a cultura não é um 'objeto’ em via de extinção (parte II)”. Mana, 2(3):03-150.

SCHEINER, Tereza. 2012 "Repensando o Museu Integral: do conceito às práticas". Boletim do Museu Paraense Emílio Goeldi. Ciências Humanas, 7(1):15-30.

STOCKING JR., George.1985. "Objects and others”. In: STOCKING JR., G. (ed.): Objects and Others. Essays on Museums and Material Culture, pp. 3-14. Madison: University of Wisconsin Press.

TOLEDO, R. F. \& JACOBI, P. R. 2013. "Pesquisa-ação e educação: compartilhando os princípios na construção de conhecimentos e no fortalecimento comunitário para o enfrentamento de problemas". Revista Educação e Sociedade, 34(122):155-173.

VIDAL, Lux B. 2008. "O museu dos povos indígenas do Oiapoque - Kuahí. Gestão do patrimônio cultural pelos povos indígenas do Oiapoque, Amapá." In BRUNO, M. C. O. \& NEVES, K. R. F. (eds.): Museus como agentes de mudança social e desenvolvimento: Propostas e reflexões museológicas, pp. 173-182. São Cristóvão: Museu de Arqueologia do Xingó. . 2013. "Kuahí, the Indians of the lower Oiapoque and their museum". Vibrant: Virtual Brazilian Antropology, 10(2):4391-427. 
VIVEIROS DE CASTRO, Eduardo. 1996. "Os pronomes cosmológicos e o perspectivismo ameríndio". Mana, 2(2):115-144. 2015. Metafísicas canibais. São Paulo: Cosac Naify.

\begin{abstract}
The article aims to present theoretical and epistemological problems about the universe of museums and indigenous museological processes based on data, information and ethnographic experiences arising from investigations carried out during about 15 years on this field of research. We deal with pertinent questions for the constitution of an anthropology of indigenous museums, placing themes such as reflexivity, co-authorship, symmetry, horizontality, ways of validating anthropological knowledge and representation; as important aspects for the constitution of an ethnomuseological approach amid the diversity of indigenous museums in Brazil.
\end{abstract}

Keywords: Indigenous Museums, Anthropology, Ethnography, Epistemology.

Recebido em novembro de 2019.

Aprovado em janeiro 2020. 